\title{
ANALYSIS OF THE PHYSICAL AND CHEMICAL CHARACTERISTICS OF VEGETABLE OILS AS FUEL
}

\author{
Giuseppe Toscano, Eleonora Maldini
}

\section{Introduction}

At present biofuels are one of the most promising forms of renewable energy with a wide range of possible applications. In particular, applications which are based on the use of these products in diesel engines have long been studied in the research and energy industry sectors. Biofuels are products which can be derived from oleaginous crops, for the production of vegetable oils used either pure or transformed into biodiesel, or from sugary and/or starchy crops for the production of ethanol.

This paper studies in detail some aspects of vegetable oil characteristics. The attention paid to this source of energy can be attributed to a number of important positive aspects: the biodegradability, the absence of sulphur, the low content of carbon monoxide emissions, of particulate matter and of unburnt products $[6,15]$, the possibility to become more independent from fossil fuels as a source of energy and to exploit the agricultural production and the entrepreneurial systems connected with this sector.

The limitations that are found in using these oils are linked mainly to the cost, which is not competitive if compared with diesel $[7,10]$, and to the chemical and physical properties which are in part unlike those set down by the specifications for diesel engines.

Moreover it is necessary to consider the high variability of the chemical and physical characteristics of different oils and in some cases of oils derived from the same plant species.

In general these products are made up of $98 \%$ triglycerides while the remaining $2 \%$ consists of phospholipids and different types of hydrocarbons. Glycerides are formed from a molecule of esterified glycerol with molecules of fatty acids (in a range going from 1 to 3 ) which are characterised by the differ-

Paper received 20.12.2006; accepted 11.10.2007

Dott. Giuseppe Toscano researcher, Dept. SASC Technical University of Marche, g.toscano@univpm.it

Dott. Eleonora MALDini, PhD Studente, Dept. SASC Technical University of Marche, e.maldini@univpm.it ent number of carbon atoms and by the variable chemical configuration. The different chemical structure influences the variability of the characteristics of the different oils, and consequently the physical properties of the oil itself.

The aim of this paper, which is part of a wider research programme concerning the possibility to develop systems for the use of vegetable oils as a source of fuel, is to improve the understanding of the physical and chemical properties of vegetable oils and to define the possible relationships between them. A thorough understanding of this type of information will allow a more detailed definition of the performance of this product in diesel engines and, in general, in the conversion systems used for energy recovery.

\section{Main chemical and physical properties of vegetable oil as fuel}

The chemical and physical properties of a vegetable oil as fuel are numerous and are mentioned in technical regulations and suggestions $[17,19]$.

For this purpose, table 1 reports the principal parameters of oleaginous biofuels set down in technical regulations and in specifications indicated by some engine manufacturers.

The most restrictive limits refer to biodiesel destined to low power engines that required a more refined biofuel that is similar to diesel.

Table 2 summarises the properties considered in these regulations and the importance of each property when used as a fuel for diesel engines.

Viscosity is considered the most important of these properties because of the immediate and visible effects which can arise when values of this parameter are not suitable. High values of viscosity of a vegetable oil are the cause of incomplete combustion and of the consequent formation of deposits and wear on the engine $[3,9,15,16]$.

Literature $[1,9,13,15]$ shows that the viscosity of oils is directly related to the level of unsaturation and the length of the fatty acid chains. The viscosity tends to decrease when there is an increased presence of 
double bonds and grows with an increase in the length of the hydrocarbon chain and according to the level of polymerisation in the oil.

Auld [4], was one of the first researchers to elaborate an equation that expresses the relationship between the influence of the quantity of double bonds (measured by $N_{i}$ ) and the length of the hydrocarbon chain on viscosity (measured by $N_{s}$ ).

Using this equation it is possible to verify that the viscosity increases when the presence of double bonds decreases and when the length of the hydrocarbon chain increases.

The increase in the viscosity of a vegetable oil subjected to rapid heating (for example in the case of frying when a temperature of more than $200^{\circ} \mathrm{C}$ may be reached) is determined by the breaking of the double bonds and a consequent reduction in the level of unsaturation [21].

Viscosity is also connected with the configuration of the double bonds (the cis configuration determines lower viscosity than the trans configuration) while the position of the double bonds along the hydrocarbon chain has less effect [15].

Other works in literature $[1,2,20]$ show further relationships between viscosity and chemical parameters such as $N_{i}$ and $N_{s}$, or more generally the acidic composition of triglycerides.

The viscosity of the vegetable oil is closely dependent on temperature. An increase in temperature corresponds to a non-linear reduction in viscosity. A great number of equations have been drawn up by researchers $[1,11]$, but the expression that best explains the relationship between temperature and viscosity is found in equations (1) and (2):

$$
\begin{aligned}
& \ln v=a+\frac{b}{T}+\frac{c}{T^{2}} \\
& \ln v=a+\frac{b}{T}+c \cdot T
\end{aligned}
$$

where $v$ is the kinematic viscosity at temperature $T, a$, $b$ and $c$ are constant.

Recent studies [7] have found a relationship between the chemical structure of oil and the calorific value, expressed by a mathematical equation which illustrates the correlation between $N_{s}$ and $N_{i}$ and $H C V$.

The equation is as follows:

$$
H C V=49.43-\left[0.041\left(N_{s}\right)+0.015\left(N_{i}\right)\right]
$$

The $H C V$ decreases when $N_{i}$ and $N_{s}$ increase, implying that the energy content increases in accordance with the increase in the length of the chain, and therefore with the increase in carbon atoms, but decreases when the percentage of carbon decreases with respect to the oxygen. Moreover, the calorific content of the fuel decreases in accordance with the reduction in the hydrogen content, and therefore as the $N_{i}$ increases (that is to say when the number of double bonds increases).

\begin{tabular}{|l|c|c|c|c|c|c|}
\hline & & \multicolumn{3}{|c|}{ VEGETABLE OIL } & \multicolumn{2}{c|}{ BIODIESEL } \\
\hline \multicolumn{1}{|c|}{ PARAMETER } & UNIT & LOW SPEED & HIGH SPEED & DIN 51605 & EU & USA \\
\hline Density $\left(15^{\circ} \mathrm{C}\right)$ & & ENGINE $^{(1)}$ & ENGINE $^{(2)}$ & & EN 14214 & ASTM D6751 \\
\hline Kinematic viscosity $\left(40^{\circ} \mathrm{C}\right)$ & $10^{-6} \mathrm{~m}^{2} / \mathrm{s}$ & $2.0-100$ & $<38$ & $<38$ & $3.5-5$ & $1.9-6$ \\
\hline Flash point & ${ }^{\circ} \mathrm{C}$ & $>100$ & $>220$ & $>220$ & $>120$ & $>130$ \\
\hline Calorific Value & $\mathrm{kJ} / \mathrm{kg}$ & - & $>35000$ & $>35000$ & - & - \\
\hline Carbon Residue & $\% \mathrm{~m} / \mathrm{m}$ & $<0.3$ & $<0.48$ & $<0.48$ & $<0.3$ & $<0.5$ \\
\hline Iodine Number & & $<140$ & $100-120$ & $100-120$ & $<120$ & - \\
\hline Sulphur Content & $\mathrm{mg} / \mathrm{kg}$ & $<50$ & $<20$ & $<10$ & $<10$ & $<15$ \\
\hline Contamination & $\mathrm{mg} / \mathrm{kg}$ & $<50$ & $<25$ & $<25$ & $<24$ & $<24$ \\
\hline Oxidation Stability $\left(110^{\circ} \mathrm{C}\right)$ & $\mathrm{h}$ & - & $>5$ & $>5$ & $>5$ & $>5$ \\
\hline Phosphorous Content & $\mathrm{mg} / \mathrm{kg}$ & $<80$ & $<15$ & $<12$ & $<10$ & $<10$ \\
\hline Ash Content & $\% \mathrm{~m} / \mathrm{m}$ & $<0.02$ & $<0.01$ & $<0.01$ & $<0.02$ & $<0.02$ \\
\hline Water Content & $\% \mathrm{~m} / \mathrm{m}$ & $<0.2$ & $<0.075$ & $<0.075$ & $<0.5$ & $<0.5$ \\
\hline Acid Value & $\mathrm{mg} \mathrm{KOH} / \mathrm{g}$ & $<5$ & $<2$ & $<2$ & $<0.5$ & $<0.5$ \\
\hline Alkali Metals $(\mathrm{Ca}+\mathrm{Mg})$ & $\mathrm{mg} / \mathrm{kg}$ & $<50$ & - & $<20$ & - & - \\
\hline
\end{tabular}

(1) Source: Wärtsilä. Liquid Bio Fuel Specification (2003)

(2) Source: Quality Standard For Rapeseed Oil. RK-Qualitatstandard 05-2000

TABLE 1 - Specifications and technical regulations of vegetable oil and biodiesel characterization. 


\begin{tabular}{|c|c|c|}
\hline PROPERTY & DESCRIPTION & COMMENTS \\
\hline Density & Mass of the unit of volume & $\begin{array}{l}\text { Influences the performance of the oil in the } \\
\text { injectors }\end{array}$ \\
\hline Viscosity $(v)$ & $\begin{array}{l}\text { Resistance between the adjacent layers of a fluid, which } \\
\text { hinders the sliding of one over the other }\end{array}$ & $\begin{array}{l}\text { Important for the fuel and injection supply } \\
\text { of the engines }\end{array}$ \\
\hline Calorific Value $(\mathrm{CV})$ & $\begin{array}{l}\text { The energy released by a fuel during the combustion } \\
\text { process. Higher calorific value }(H C V) \text { indicates all the } \\
\text { energy produced by the fuel, lower calorific value } \\
(L C V) \text { on the contrary does not consider the latent heat } \\
\text { of the vaporisation of water produced by the chemical } \\
\text { reaction of hydrogen with oxygen }\end{array}$ & Influences specific consumption \\
\hline Cetane number & Indicates performance on ignition & $\begin{array}{l}\text { Influences cold start, combustion and noise } \\
\text { of the engine }\end{array}$ \\
\hline Melting Point & $\begin{array}{l}\text { Indicates the temperature at which the transformation } \\
\text { from solid to liquid state can be observed in standard } \\
\text { conditions }\end{array}$ & $\begin{array}{l}\text { High melting point values can cause } \\
\text { problems on flow in the fuel supply }\end{array}$ \\
\hline Flash Point & $\begin{array}{l}\text { The minimum temperature at which the vapours of a } \\
\text { fuel catch fire if in contact with a flame }\end{array}$ & $\begin{array}{l}\text { The higher this value is, the safer storage, } \\
\text { transport and manipulation of the product } \\
\text { will be }\end{array}$ \\
\hline Oxidation stability & $\begin{array}{l}\text { Indicates the quantity of gum and macromolecules } \\
\text { which are formed when subjecting a sample to certain } \\
\text { conditions of pressure in the presence of oxygen }\end{array}$ & $\begin{array}{l}\text { The compounds generated cause an } \\
\text { increase in viscosity }\end{array}$ \\
\hline Phosphorus content & Measures the phosphatide content & $\begin{array}{l}\text { Phosphatides may form gum in the tanks, in } \\
\text { the feed pipes and the filters }\end{array}$ \\
\hline Carbon residue & $\begin{array}{l}\text { Measures the presence at high temperatures of some } \\
\text { natural compounds with high molecular weight }\end{array}$ & $\begin{array}{l}\text { At high temperatures some compounds } \\
\text { decompose giving rise to carbon residues }\end{array}$ \\
\hline Sediment content & Measure the sediment content & $\begin{array}{l}\text { The sediment can shorten filter life or plug } \\
\text { fuel filter, and affect the quality of fuel }\end{array}$ \\
\hline Water content & Measure the water content & $\begin{array}{l}\text { The water can shorten filter life or plug fuel } \\
\text { filter and promote fuel corrosion and } \\
\text { microbial growth }\end{array}$ \\
\hline $\mathrm{Na}+\mathrm{K}$ content & Measure the $\mathrm{Na}$ and $\mathrm{K}$ content & $\begin{array}{l}\text { Residual } \mathrm{Na} \text { and } \mathrm{K} \text { can form deposits in fuel } \\
\text { injection system components, form high ash } \\
\text { levels in the engine and poison emission } \\
\text { control aftertreatment systems }\end{array}$ \\
\hline $\mathrm{Ca}+\mathrm{Mg}$ content & Measure the $\mathrm{Ca}$ and $\mathrm{Mg}$ content & $\begin{array}{l}\text { Residual } \mathrm{Ca} \text { and } \mathrm{Mg} \text { can form deposits in } \\
\text { fuel injection system components, form high } \\
\text { ash levels in the engine and poison emission } \\
\text { control aftertreatment systems }\end{array}$ \\
\hline Acid value & Indicates the concentration of free fatty acids & $\begin{array}{l}\text { At high temperatures free fatty acids form } \\
\text { salts with the metal and may damage the } \\
\text { engine or the tanks }\end{array}$ \\
\hline Iodine number $\left(N_{i}\right)$ & $\begin{array}{l}\text { Indicates the level of unsaturation of the oil, that is to } \\
\text { say the presence of double bonds between carbon atoms }\end{array}$ & $\begin{array}{l}\text { Double bonds are more susceptible than } \\
\text { single bonds to reaction with oxygen and } \\
\text { generally cause the formation of gum }\end{array}$ \\
\hline $\begin{array}{l}\text { Saponification number } \\
\left(N_{s}\right)\end{array}$ & $\begin{array}{l}\text { Estimates the content in fatty acids either free or bound } \\
\text { to the glycerol of a vegetable oil }\end{array}$ & $\begin{array}{l}\text { The higher this value is, the lower the } \\
\text { molecular weight of the acids will be }\end{array}$ \\
\hline
\end{tabular}

TABLE 2 - Description of the main chemical and physical properties of vegetable oils as a source of energy.

There is a close dependence between the chemical structure of the oil and the cetane number, which is another fundamental parameter for the efficiency of combustion. Long, saturate and unbranched chains have a high cetane number. On the contrary, branched, short and unsaturated chains have a low cetane number, with consequent difficulty in starting combustion. If the unsaturation is situated at the end of the hydrocarbon chain the cetane number is higher.

In vegetable oils the filtrability limits and cloud 


\begin{tabular}{|c|c|c|c|}
\hline $\begin{array}{c}\text { PHYSICAL } \\
\text { PROPERTIES }\end{array}$ & \multicolumn{4}{|c|}{ CHEMICAL CHARACTERISTICS } \\
\hline & Unsaturation & Chain Length & Branching \\
\hline Viscosity & - & + & + \\
\hline HCV & - & + & $/$ \\
\hline Cetane number ${ }^{(1)}$ & - & + & - \\
\hline Flash point & + & + & $/$ \\
\hline Oxidation stability & - & $/$ & $/$ \\
\hline $\begin{array}{c}\text { Filtrability limit } \\
\text { and cloud point }\end{array}$ & - & - & $/$ \\
\hline Specific heat & - & + & $/$ \\
\hline
\end{tabular}

Notes: (+) positive relationship; (-) negative relationship; (/) no relationship.

(1) The cetane number is also in function of other chemical parameters such as: the presence of aromatic compounds (the greater the number of aromatic compounds, the lower the cetane number will be) and the position of the double bonds (the closer the double bond is to the end, the greater the cetane number will be).

TABLE 3 - Influence of chemical characteristics on physical properties.

points are a function of the fatty acid composition. Vegetable oils, which are prevalently made up of saturate fatty acids, have a high melting point and show higher filterability limits and cloud points than oils which have a prevalence of unsaturated fatty acids.

The presence of double bonds and the length of the fatty acid chain also influence the flash point. The longer the hydrocarbon chain and the higher the level of unsaturation of the vegetable oil is, the higher the flash point will be.
Finally the specific heat must be considered, defined as the amount of heat per unit mass required to raise the temperature by $1^{\circ} \mathrm{C}$. This parameter is a physical property which can be decisive for planning storage and temperature maintenance systems for the oils which tend to solidify at low temperatures. This parameter has been found to increase with an increase in saturation, that is to say, when the double bonds decrease [18]. Table 3 summarises the abovementioned points.

\section{Materials and methods}

\subsection{Materials}

For the purpose of this analysis 19 samples of vegetable oil of different types and origin were considered (Table 4). Some of these products were obtained through extraction with a mechanical press and subsequent filtering. The other oils were procured from large-scale retailers or plants which use vegetable oils for the production of electricity.

Several chemical and physical analyses were carried out on each oil sample. In particular, for the physical analyses the viscosity and the specific heat were determined, while for the chemical analyses the iodine number and the saponification number were determined, together with the elemental analysis.

\subsection{Chemical and physical analyses}

In detail, viscosity was measured according to the DIN EN ISO 3104 regulations, using a CannonFenske capillary viscometer immersed in a thermostatic bath. The measurements of viscosity were carried out at different temperatures in a range of between

\begin{tabular}{|l|c|c|}
\hline \multicolumn{1}{|c|}{ TYPE OF OIL } & $\begin{array}{c}\text { NUMBER OF } \\
\text { SAMPLES }\end{array}$ & NOTES \\
\hline Helianthus annuus L. (sunflower oil) & 4 & $\begin{array}{c}\text { Samples taken partly from large-scale retailers and partly from } \\
\text { mechanical extraction and filtering }\end{array}$ \\
\hline Cynara cardunculus L. (cynara oil) & 2 & Obtained by mechanical extraction and filtering \\
\hline Brassica carinata L. (brassica oil) & 3 & Obtained by mechanical extraction and filtering \\
\hline Linum usitatissimum L. ( linseed oil) & 1 & Taken from large-scale retailers \\
\hline $\begin{array}{l}\text { Stearin (fraction of Elaeis guineensis } \\
\text { Jacq) }\end{array}$ & 1 & Taken from large-scale retailers \\
\hline Elaeis guineensis Jacq (palm oil) & 2 & Taken from large-scale retailers \\
\hline Zea mays L.(corn oil) & 2 & Taken from large-scale retailers \\
\hline Glicine max L. (soybeen oil) & 2 & Taken from large-scale retailers \\
\hline Brassica napus L. (rapeseed oil) & 1 & Taken from large-scale retailers \\
\hline Argania spinosa L. (argan oil) & 1 & Taken from large-scale retailers \\
\hline TOTAL & 19 & \\
\hline
\end{tabular}

TABLE 4 - Description of the samples used in the analysis. 
$30^{\circ} \mathrm{C}$ and $70^{\circ} \mathrm{C}$ at intervals of $10^{\circ} \mathrm{C}$ for a total of 5 measurements, each of which was obtained by averaging the values of three repetitions.

The determination of the Higher Calorific Value was carried out using an IKA C2000 isoperibolic calorimeter. Specifically, this instrument allows the $H C V$ to be determined through bomb calorimetry in accordance with CEN/TS 14918 regulations. For $H C V$, two repetitions were carried out for each vegetable oil sample. Subsequently, on the basis of the values found in the elemental analysis, the $L C V$ was calculated according to the abovementioned regulations.

Measurement of the elemental analysis was performed using the Perkin Elmer $2400 \mathrm{CHNS} / \mathrm{O}$ analyser. For this calculation the prCEN/TS 15104 regulations were followed. This instrument determines the carbon, hydrogen and nitrogen content by means of thermal conductivity detection $(T C D)$ which identifies the single components produced by the combustion of the sample, separating them by means of a chromatographic column.

Even in this case two repetitions were carried out for each sample of oil in order to calculate the average value.

As far as the determination of $N_{i}$ is concerned, the analysis was carried out on the basis of the indications in DIN 53241-1 regulations. This measurement is based on the titration, by means of the Wijs reagent, of the excess of a known quantity of halogenated reagent which does not react with the vegetable oil.

The values given to each oil sample represent the average value obtained from two repetitions.

For $N_{s}$, the procedure followed was in accordance with DIN 51159-2 regulations. The measurement of this parameter is based on the determination with a titration using hydrochloric acid of the $\mathrm{KOH}$ necessary to saponify a known quantity of the oil sample. As in the case of the previous chemical parameter, the saponification number was also calculated from the average of two repetitions for each oil sample.

\subsection{Data processing}

The data collected during the trial allowed a series of analyses to be developed to verify the existence of links between the physical and the chemical parameters of the vegetable oils. One of the first aspects studied was the determination of the relationship between the viscosity of the vegetable oil and its temperature. For this purpose Tablecurve 2D v5.0 software was used to obtain a series of mathematical equations which relate the parameters studied.

In order to define the relationship between the viscosity and the temperature, mathematical equations were chosen since they were considered to be the most reliable. These equations are characterised by the highest regression coefficient values.

Other types of mathematical relationships investigated in this work, were analysed using MINITAB ${ }^{\circledR}$ Release 14.1. In particular this analysis considered the possible relationships between viscosity and temperature, the $N_{i}$, and the $N_{s}$ as well as the relationship between the calorific value, the $N_{i}$ and the $N_{s}$. In detail, a multiple regression analysis was carried out between the viscosity and $N_{i}$ and $N_{s}$, and simple regressions between viscosity and $N_{i}$ and $N_{s}$, and $L C V$ and $N_{s}$. The software allowed the definition of equations with indicators for verifying the reliability of the analysis, such as the p-value which represents the lowest meaningful level of the test for which the null hypothesis is rejected, that is to say when there are no correlations between the variables considered. The level was fixed at $0.05(5 \%)$, therefore with any values below this level it is possible to reject the null hypothesis with low probability of making a mistake.

\section{Results and discussion}

Table 5 summarises the results of the chemical and physical analyses carried out on the vegetable oils considered in this paper.

As expected, the results show a reduction in the viscosity of the oil as its temperature increases. In general terms, comparing the values of viscosity at temperatures ranging from $30^{\circ} \mathrm{C}$ to $70^{\circ} \mathrm{C}$, it is possible to see an average reduction in this parameter of about $70 \%$. The trend is relatively similar for the different oils, with viscosity reduction levels varying between $74 \%$ for palm oil and $68.9 \%$ for soybean oil.

It is interesting to observe how the differences in viscosity for the various oils, in the same temperature conditions, vary greatly within the temperature range studied. In particular at a temperature of $30^{\circ} \mathrm{C}$ the absolute differences are about $29.42 \cdot 10^{-6} \mathrm{~m}^{2} / \mathrm{s}$ compared with $4.17 \cdot 10^{-6} \mathrm{~m}^{2} / \mathrm{s}$ at a temperature of $70^{\circ} \mathrm{C}$.

Processing with Tablecurve 2D v5.0 software gave the most probable equations which link the values of the viscosity of each oil with its temperature (4), (5), (6). The relationships in which the $\mathrm{R}^{2}$ value is greater than 0.999 and the p-value is under the $5 \%$ limit are illustrated below:

$$
\begin{gathered}
v=a+b e \\
\ln v=a+b \sqrt{T} \\
v=a+\frac{b}{T}
\end{gathered}
$$

where $v$ is the kinematic viscosity, $T$ is the temperature, $a, b$ and $c$ are constant.

Equation (7) expresses the relationship between viscosity at $40^{\circ} \mathrm{C}$ (temperature fixed by the reference regulations) and the values of $N_{i}$ and $N_{s}$, obtained by multiple regression analysis. In particular:

$$
v\left(40^{\circ} \mathrm{C}\right)=146-0.488 N_{s}-0.149 N_{i}
$$

where $v$ is the viscosity in $10^{-6} \mathrm{~m}^{2} / \mathrm{s}, N_{s}$ is the saponification number and $N_{i}$ is the iodine number. 
The equation has an $\mathrm{R}^{2}$ coefficient of 0.891 and a $\mathrm{p}$-value lower than 0.01 .

A study of the single relationships between the viscosity and the abovementioned parameters highlights some interesting details. In particular, the analysis of the relationship between viscosity and $N_{i}$ (Fig.1) shows an $\mathrm{R}^{2}$ value of 0.505 and a p-value lower than 0.01 . However, by excluding from the analysis the value which is furthest from the line, in this case the viscosity of Brassica carinata oil, the correlation becomes considerably higher, with $\mathrm{R}^{2}$ values of 0.967 and a p-value of less than 0.01 .

Equation (8) expresses the latter relationship:

$$
v\left(40^{\circ} \mathrm{C}\right)=48.6-0.120 N_{i}
$$

In other words, with an increase in $N_{i}$, and therefore in the presence of double bonds, the viscosity decreases in a linear way. More precisely, the variation

\begin{tabular}{|c|c|c|c|c|c|c|c|c|c|}
\hline \multirow[b]{2}{*}{ TYPE OF OIL } & \multicolumn{5}{|c|}{ VISCOSITY $v\left(10^{-6} \mathrm{~m}^{2} / \mathrm{s}\right)$} & \multirow{2}{*}{\begin{tabular}{|c|}
$N_{S}$ \\
$\mathrm{mgKOH} /$ \\
$100 \mathrm{~g}$ \\
\end{tabular}} & \multirow{2}{*}{$\frac{N_{I}}{\mathrm{gI}_{2} / 100 \mathrm{~g}}$} & \multirow{2}{*}{$\frac{H C V}{\mathrm{~J} / \mathrm{g}}$} & \multirow{2}{*}{$\frac{L C V}{\mathrm{~J} / \mathrm{g}}$} \\
\hline & $30^{\circ} \mathrm{C}$ & $40^{\circ} \mathrm{C}$ & $50^{\circ} \mathrm{C}$ & $60^{\circ} \mathrm{C}$ & $70^{\circ} \mathrm{C}$ & & & & \\
\hline $\begin{array}{l}\text { Helianthus annuus (sunflower } \\
\text { oil n.1) }\end{array}$ & 50.86 & 35.65 & 25.77 & 19.40 & 15.05 & 191.25 & 113.9 & 39253 & 36830 \\
\hline $\begin{array}{l}\text { Cynara cardunculus (cynara } \\
\text { oil n.1) }\end{array}$ & 47.35 & 32.98 & 24.15 & 18.34 & 14.45 & 188.30 & 124.5 & 39374 & 36946 \\
\hline $\begin{array}{l}\text { Brassica carinata (brassica oil } \\
\text { n.1) }\end{array}$ & 63.92 & 43.94 & 31.73 & 23.68 & 18.31 & 177.60 & 111.7 & 39926 & 37394 \\
\hline $\begin{array}{l}\text { Linum usitatissimum (linseed } \\
\text { oil) }\end{array}$ & 36.54 & 26.47 & 19.94 & 15.53 & 12.71 & 193.65 & 188.2 & 38978 & 36841 \\
\hline $\begin{array}{l}\text { Stearine (fraction of Elaeis } \\
\text { guineensis) }\end{array}$ & & & 31.30 & 22.97 & 17.43 & 201.73 & 37.6 & 39208 & 36691 \\
\hline $\begin{array}{l}\text { Helianthus annus (sunflower } \\
\text { oil n.2) }\end{array}$ & 51.02 & 35.44 & 25.64 & 19.33 & 15.40 & 193.53 & 112.5 & 39220 & 36744 \\
\hline $\begin{array}{l}\text { Helianthus annus (sunflower } \\
\text { oil n.3) }\end{array}$ & 45.05 & 32.19 & 23.65 & 18.59 & 14.14 & 193.20 & 134.4 & 39442 & 36938 \\
\hline $\begin{array}{l}\text { Elaeis guineensis (palm oil } \\
\text { n.1) }\end{array}$ & 62.75 & 42.48 & 29.99 & 22.13 & 16.95 & 200.13 & 52.5 & 38903 & 36312 \\
\hline Zea mays (corn oil n.1) & 48.83 & 34.05 & 24.81 & 18.79 & 14.68 & 192.52 & 122.6 & 39114 & 36648 \\
\hline Glycine max (soybeen oil n.1) & 48.20 & 34.25 & 25.10 & 19.08 & 14.91 & 194.20 & 119.6 & 38811 & 36371 \\
\hline Argania spinosa (argan oil) & 52.44 & 36.12 & 26.06 & 19.59 & 15.15 & 193.70 & 91.0 & 39229 & 36661 \\
\hline $\begin{array}{l}\text { Brassica napus (rapeseed oil } \\
\text { n.1) }\end{array}$ & 52.75 & 37.53 & 27.14 & 20.43 & 15.84 & 190.95 & 100.1 & 39547 & 37009 \\
\hline $\begin{array}{l}\text { Elaeis guineensis (palm oil } \\
\mathrm{n} .2 \text { ) }\end{array}$ & 65.96 & 43.40 & 30.59 & 22.46 & 17.10 & 199.07 & 47.8 & 39205 & 36644 \\
\hline $\begin{array}{l}\text { Cynara cardunculus (cynara } \\
\text { oil n.2) }\end{array}$ & 47.98 & 33.60 & 24.55 & 18.60 & 14.79 & & 128.9 & 39424 & 36975 \\
\hline $\begin{array}{l}\text { Brassica carinata (brassica oil } \\
\mathrm{n} .2)^{(1)}\end{array}$ & 64.02 & 44.22 & 31.90 & 23.93 & & 176.60 & 111.7 & 39832 & 37315 \\
\hline $\begin{array}{l}\text { Brassica carinata (brassica oil } \\
\text { n. } 3)^{(2)}\end{array}$ & 63.50 & 43.96 & 31.88 & 23.87 & 19.14 & 178.60 & 111.7 & 40052 & 37482 \\
\hline $\begin{array}{l}\text { Helianthus annus (sunflower } \\
\text { oil n.4) }\end{array}$ & 46.06 & 33.25 & 24.39 & 18.58 & 14.58 & 190.30 & 117.6 & 39564 & 37060 \\
\hline Zea mays (corn oil n.2) & 48.33 & 34.38 & 25.10 & 19.00 & 14.84 & 189.98 & 121.3 & 39461 & 36910 \\
\hline Glycine $\max$ (soybean oil n.2) & 46.74 & 33.41 & 24.48 & 18.59 & 14.54 & 190.08 & 123.7 & 39475 & 36982 \\
\hline Min & 35.54 & 26.47 & 19.94 & 15.53 & 12.71 & 176.60 & 37.6 & 38811 & 36312 \\
\hline Max & 65.96 & 44.22 & 31.90 & 23.93 & 19.14 & 201.73 & 188.2 & 40052 & 37482 \\
\hline Average & 52.35 & 36.52 & 26.75 & 20.15 & 15.56 & 190.85 & 109.0 & 39369 & 36881 \\
\hline
\end{tabular}

${ }^{(1)}$ Brassica carinata oil obtained with low pressure extraction

(2) Brassica carinata oil obtained with high pressure extraction

TABLE 5 - Values of viscosity at different temperatures, saponification number, iodine number, and higher and lower calorific values of the vegetable oils studied. 


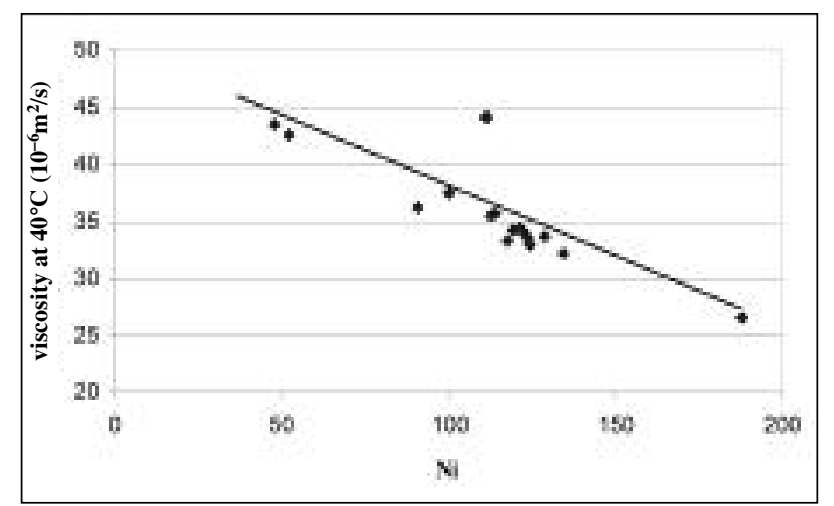

Fig. 1 - Viscosity and $\mathrm{N}_{\mathrm{i}}$ correlation line.

in $N_{i}$ from 85 to 120 (corresponding to high oleic sunflower seed oil and ordinary sunflower seed oil respectively), determines a reduction in viscosity of about $11 \%$.

Figure 2 shows the relationship between $N_{s}$ and viscosity. Considering the values of all the samples the relationship is not significant, since an $\mathrm{R}^{2}$ of 0.108 and a p-value of 0.107 are obtained. If the two values which are significantly distant from the straight line, corresponding to the two samples of palm oil, are omitted the relationship becomes meaningful, with an $\mathrm{R}^{2}$ of 0.703 and a $\mathrm{p}$-value lower than 0.01 . The equation which expresses this relationship is as follows:

$$
v\left(40^{\circ} \mathrm{C}\right)=164-0.679 \mathrm{~N}_{s}
$$

In general therefore, when $N_{s}$ (that is to say the average length of the fatty acid chains), increases, the value of viscosity decreases. In particular, by increasing the $N_{s}$ from 175 to 195 (corresponding to brassica oil and sunflower seed oil respectively), the viscosity goes down by $30.7 \%$.

The investigation of the relationship between the $L C V$ and the chemical parameters studied highlighted a link only between $L C V$ and the $N_{s}$ value. In particular, the corresponding equation (10) shows an $\mathrm{R}^{2}$ of 0.750 and a $\mathrm{p}$-value of less than 0.01 :

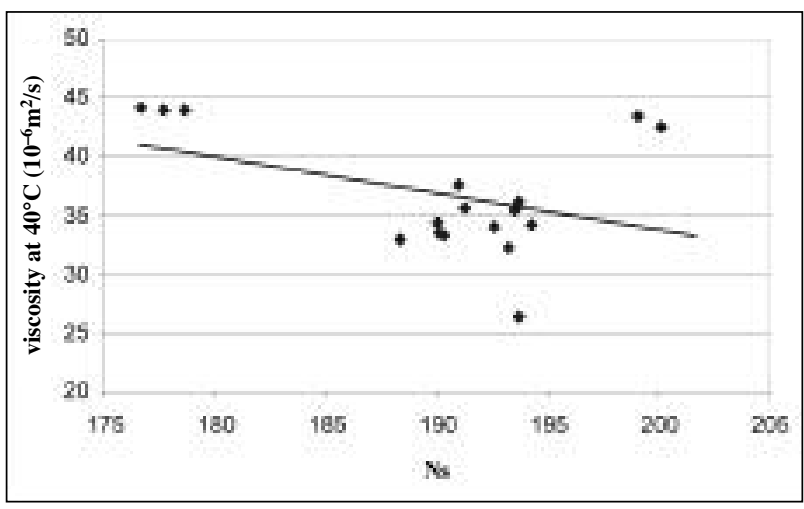

Fig. 2 - Viscosity and $\mathrm{N}_{\mathrm{s}}$ correlation line.

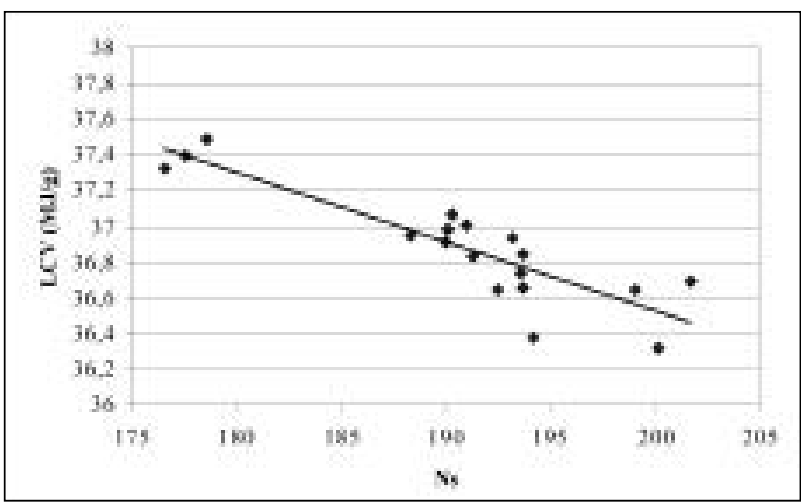

Fig. 3 - LCV and $\mathrm{N}_{\mathrm{s}}$ correlation line.

$$
L C V=44290-38.8 N_{s}
$$

The differences in terms of energy between vegetable oils which have very different chemical structures are generally rather limited being of about $3 \%$.

Finally, the results are shown of the analysis aimed at verifying any effects of double bonds and the length of the fatty acid carbon chain on the performance of the viscosity of the oils according to variations in temperature. Table 6 gives a detailed summary of the data which express the quality of the relationships between the coefficients of equations (4),

\begin{tabular}{|c|c|c|c|c|c|}
\hline equations & $\begin{array}{c}\text { reference } \\
\text { parameters }\end{array}$ & & $\mathbf{a}$ & b & c \\
\hline \multirow{2}{*}{$\mathrm{i}=\mathrm{a}+\mathrm{b} \mathrm{e}^{-\mathrm{T} / \mathrm{c}}$} & \multirow{2}{*}{ Ni; Ns } & $\mathrm{R}^{2}$ & 0,548 & 0,801 & 0,169 \\
\hline & & $\mathrm{p}$ & 0,001 & 0,000 & 0,098 \\
\hline \multirow{2}{*}{$\operatorname{lní}=a+b T^{0,5}$} & \multirow{2}{*}{$\mathrm{Ni}$; Ns } & $\mathrm{R}^{2}$ & 0,946 & 0,912 & \\
\hline & & $\mathrm{p}$ & 0,000 & 0,000 & \\
\hline \multirow{2}{*}{$\mathrm{v}=\mathrm{a}+\mathrm{b} / \mathrm{T}$} & \multirow{2}{*}{ Ni; Ns } & $\mathrm{R}^{2}$ & 0,897 & 0,905 & \\
\hline & & $p$ & 0,000 & 0,000 & \\
\hline
\end{tabular}
(5) and (6) and the values of $N_{i}$ and $N_{s}$.

TABLE 6 - Values of correlations between $\mathrm{N}_{\mathrm{i}}$ and $\mathrm{N}_{\mathrm{s}}$ and the coefficients of equations $v=f(\mathrm{~T})$.

Interesting relationships can be seen between $N_{i}$ and $N_{s}$ and the coefficients of equations (4), (5) and (6). However, in the case of equation (4) only coefficient $b$ seems to be significantly related to $N_{i}$ and $N_{s}$.

\section{Remarks}

The results illustrated in this paper contribute towards improving understanding of the problems related to using vegetable oils as a source of energy. In particular, the analysis of the viscosity can be considered interesting given the importance of this parameter for the performance of the oils in diesel engines.

The results show that temperature has a key role in controlling the level of viscosity of the oils. However, the relationship between viscosity and temperature of 
the oils varies according to the type of product.

In general the difference in the values of viscosity of the oils decreases when the temperature increases. Moreover, all the oils considered in this study have a viscosity of less than $20 \cdot 10^{-6} \mathrm{~m}^{2} / \mathrm{s}$ when heated to $70^{\circ} \mathrm{C}$.

Except for brassica oil and palm oil and stearin, the data regarding the viscosity of the oils studied are within the limits set by the technical regulation DIN 51605.

At a temperature of $100^{\circ} \mathrm{C}$ it is possible to obtain an oil viscosity value close to $9-10 \cdot 10^{-6} \mathrm{~m}^{2} / \mathrm{s}$, which is similar to diesel and biodiesel (about $3 \cdot 10^{-6} \mathrm{~m}^{2} / \mathrm{s}$ and $4-6 \cdot 10^{-6} \mathrm{~m}^{2} / \mathrm{s}$ respectively).

In practice the pre-heating of vegetable oil can easily be obtained using a heat exchanger which recovers the heat from the cooling system of the engine. The lack of a system which heats the oil may cause some problems connected with high viscosity above all during the winter or in cold climates. For example, considering an average temperature of $10^{\circ} \mathrm{C}$ and applying the equations obtained, the viscosity reaches values of greater than $120 \cdot 10^{-6} \mathrm{~m}^{2} / \mathrm{s}$, and in the case of temperatures below zero the viscosity can be estimated at over $200 \cdot 10^{-6} \mathrm{~m}^{2} / \mathrm{s}$.

Of the oils considered linseed oil seems to be the one which has the best performance at low temperatures, keeping the lowest viscosity, while both palm oil and palm stearin have the worst performance.

This study illustrates that the chemical structure of the tryglicerides contained in a vegetable oil conditions to a great extent the physical, mechanical and energy characteristics of the oil.

The length of the carbon chains, identified by the $N_{s}$ and the unsaturation level, indicated as $N_{i}$, are related to the value of viscosity of the oil.

In particular this aspect is underlined by the excellent results of the multiple regression which, considering all the values including palm and brassica oils with their atypical performance, confirms the existence of complementary and complex interactions between the chemical structure and the physical properties of a vegetable oil.

As far as the energy content of the oil is concerned the study illustrates that the calorific value increases when there is a reduction in $N_{s}$. Presumably the longer carbon chain influences the relationship between carbon and oxygen and therefore the greater capacity to release thermal energy in combustion. In other words, oils with long carbon chains have a greater carbon content and consequently a higher calorific value.

The results of this study also provide some initial indications about the qualitative characteristics of vegetable oil used as a source of energy. From an initial approximation it is difficult to fix optimum values of the chemical parameters which satisfy all the physical requirements of the oil necessary for a correct use in energy conversion systems. For example if, on the one hand, high $N_{i}$ values in the vegetable oil offer advantages from the point of view of viscosity, on the other hand these values reduce the cetane number. This as- pect means that it is necessary to find a compromise between the different chemical parameters. Experience in this field suggests the choice of an oil characterised by a high percentage of monounsaturated fatty acids $\left(N_{i}\right.$ of about 80$)$ and a medium length carbon chain $\left(N_{s}\right.$ about 180-190). None of the oils analysed in this study showed optimum values for all the parameters; the products which are closest to these levels are argan oil (Argania spinosa L) and rape oil (Brassica napus L). An alternative hypothesis could be to formulate suitable combinations of oils to permit greater similarity with the qualitative reference parameters.

\section{Conclusions}

The biofuel and vegetable oil market is characterised by products with uncertain and inconstant qualitative characteristics. This should encourage the research and development of a method of standardisation of energy materials in order to assess the economic and technical validity of the products. Standardisation of this type must be based on the development of a thorough understanding of the chemical and physical properties of the vegetable oils and their performance. This study illustrates that the physical and mechanical features of the product reflect the chemical properties of the vegetable oils. The possibility to construct models for the performance of an oil is essential in order to develop simplified methods for controlling its quality and for predicting its energy transformation. In other words, the simple determination of the chemical parameters considered in this study could be of assistance for expressing an evaluation of the properties of an unknown vegetable oil. In conclusion, the study of the performance of the oils through an analysis of the chemical characteristics contributes to the improvement of the technology used for energy transformation and to the development of new technical solutions for planning conversion plants.

\section{References}

[1] Abramovic H., Klofutar C. (1998): “The temperature dependence of dynamic viscosity for some vegetable oils", Acta Chim. Slov. 45 (1), 69-77.

[2] Allen C.A.W., WatTs K.C., ACKMAN R.G. (1999): "Predicting the viscosity of biodiesel fuels from their fatty acid ester composition”, Fuel 78, 1319-1326.

[3] Altin R., Cetinkaya S., Yucesu H.S., (2001), "The potential of using vegetable oil fuels as fuel for diesel engines", Energy Conversion and Management, 42, 529-538.

[4] Bettis B.L., Peterson L., Auld D.L., Driscoll J., PETERSON E.D., (1982), "Fuel characteristics of vegetable oil from oilseed crops in the Pacific Northwest”, Agronomy Journal, 74 (March/April, 335-39.

[5] Chu Y., Kung Y. (1998): "A study on vegetable oil blends ", Food Chemistry 62, 191-195.

[6] DeRmiBAS A. (2005): "Biodiesel productionfrom vegetable oils via catalytic and non-catalytic supercriti- 
cal methanol transesterification methods", Progress in Energy and Combustion Science 31, 466-487.

[7] DeRmiBAs A., (1998): "Fuel properties and calculation of higher heating values of vegetable oils", Fuel $77(9 / 10), 1117-1120$.

[8] Eromosele C.O., Paschal N.H., (2003): “Characterization and viscosity parameters of seed oils from wild plants", Bioresource Technology 86, 203-205.

[9] Goodrum J.W., Eiteman M.A. (1996): "Physical properties of low molecular weight triglycerides for the development of biodiesel fuel models", Bioresourse Technology 56, 55-60.

[10] Graboski M., McCormick R.L. (1998): “Combustion of fat and vegetable oil derived fuels in diesel engines", Progress in Energy and Combustion Science, 24, 125-164.

[11] Gutmann F., Simmons L.M., (1952): "The temperature dependence of the viscosity of liquids", Journal of Applied Physics 23, 977-978.

[12] IGWE I.O. (2004): "The effect of temperature on the viscosity of vegetable oils in solution", Industrial crops and products 19, 185-190.

[13] KNOTHE G. (2005): "Dependence of biodiesel fuel properties on the structure of fatty acid alkyl esters", Fuel Processing Technology 86, 1059-1070.

[14] Knothe G., DunN R.O., Bagby M.O.: "Biodiesel: The use of vegetable oils and their derivatives as alternative Diesel fuels", Report Oil Chemical Research, National Center for Agricultural Utilization Research, Department of Agriculture, Peonia.

[15] Knothe G., Steidley K.R. (2005): "Kinematic viscosity of biodiesel fuel components and related compounds. Influence of compound structure and comparison to petrodiesel fuel components", Fuel 84, 1059-1065.

[16] Krisnangkura K., Yimsuman T., Pairintra R. (2006): "An empirical approach in predicting biodiesel viscosity at various temperatures", Fuel 85, 107-113.

[17] RK - Qualitatsstandard / 05-2000: "Norma bavarese per l'olio di colza".

[18] Santos J.C.O., Santos M.G.O., Dantas J.P., ConCEIÇAO M.M., ATHAide-Filho P.F. Souza A.G. (2005): "Comparative study of specific heat capacities of some vegetable oils obtained by DSC and microvawe oven", Journal of Thermal Analysis and Calorimetry 79, 283-287.

[19] SC09/GC05: "Oli e grassi vegetali, loro sottoprodotti e derivati".

[20] Toro-VAzQuez J.F., Infante-Guerrero R. (1993) Journal American Oil Chemists Society 70, 11151119 .
[21] VAldes A.F., Garcia A.B. (2006): “A study of the evolution of the physicochemical and structural characteristics of olive and sunflower oils after heating at frying temperatures”, Food Chemistry 98, 214-219.

[22] WAKABAYASHI T. (1997): "Viscosity correlation with specific gravity and molecular weight of crude oil fractions", Fuel 76, 1049-1056.

\section{SUMMARY}

Possible relationships between physical and chemical properties of vegetable oils as biofuels have been studied. 19 samples of vegetable oils of different types and origin were considered. First the relationship between the viscosity of each oil and the temperature was studied. Subsequently, single and multiple regression analyses were carried out between viscosity, iodine number, saponification number and calorific value. It was observed that temperature has a key role in controlling the level of viscosity of the oils, and the relationship between viscosity and temperature is specific to each type of product.

Moreover, the chemical structure of the tryglicerides conditions to a great extent the physical, mechanical and energy characteristics of the oil. In particular the length of the carbon chains and the unsaturation level are related to the value of viscosity in a single and multiple relationship. The calorific value increases with the increase in the length of the carbon chain.

This study could be useful to develop simplified methods for controlling the quality of vegetable oils as biofuels and for improving the technology of their energy transformation.

Key words: Vegetable oils, biofuels, physicalchemical characteristics.

\section{Symbols}

$N_{i} \quad$ Iodine Number $\left(\mathrm{gI}_{2} / 100 \mathrm{~g}\right)$

$N_{s} \quad$ Saponification Number $(\mathrm{mgKOH} / 100 \mathrm{~g})$

$\mathrm{HCV}$ High Calorific Value $(\mathrm{J} / \mathrm{g})$

$L C V$ Low Calorific Value $(\mathrm{J} / \mathrm{g})$

$v \quad$ Kinematic Viscosity $\left(10^{-6} \mathrm{~m}^{2} / \mathrm{s}\right)$

$T$ Temperature $\left({ }^{\circ} \mathrm{C}\right)$ 


\section{$3^{\text {th }}$ International Symposium \\ Actual Tasks on Agricultural Engineering 19-23 February 2007, Opatija, Croatia}

The $35^{\text {th }}$ International Symposium Actual Tasks on Agricultural Engineering was held on 19-23 February 2007 in Grand hotel "Adriatic" Opatija, Republic of Croatia. The principle Organiser, Agricultural Engineering Department, Faculty of Agriculture, University of Zagreb was supported by the following frameworks: Department of Agricultural Engineering, Faculty of Agriculture, University J.J.Strossmayer, Osijek, Department of Biosystems Engineering, Faculty of Agriculture, University of Maribor (Slovenia), Agricultural Institute of Slovenia, Hungarian Institute of Agricultural Engineering Gödöllö and Croatian Agricultural Engineering Society. Co-sponsors of the Symposium were CIGR, EurAgEng, AAAE and Association of Agricultural Engineers of South Eastern Europe (AAESEE).

This year 106 participants from 15 countries attended Symposium. It consisted of an Opening Session and six Topic Sessions covering all the broad subject-areas that fall under the scope of Agricultural Engineering. The importance of the Event was underlined by the presence of the Past President of EurAgEng Prof. Daniele De Wrachien, the representatives of the National Societies of Agricultural Engineers of Bosnia and Herzegovina Prof. S. Skaljic, Romania Prof. V. Ros, Serbia Prof. M. Martinov and Prof. M. Djevic and Croatia Prof. Silvio Kosutic.

At the Opening Session prof. dr. Edi Maletic, vice Dean of the Faculty of Agriculture, University of Zagreb and prof. dr. Vlado Guberac, Dean of the Faculty of Agriculture, University J.J. Strossmayer Osijek, made their speeches emphasising the importance of the event and its long tradition. The Convenor, Prof. Silvio Kosutic brought the greetings of the Croatian Society of Agricultural Engineering. Prof. Daniele De Wrachien stressed the long tradition of the Symposia and their future role as one of the main gathering Events for agricultural engineers in South-Eastern Europe, and pointed out the dimension of the tasks and challenges that agricultural engineering education in European universities will have to face and cope with in the third millennium. Prof. dr. Milan Djevic the representative of the Faculty of Agriculture Belgrade, Serbia closed up the Session bringing the greetings of his Faculty to the Symposium's audience. Next, a number of lectures were held, among which are worth mentioning: "Agricultural engineering in South-East Europe, status and prospects" presented by Prof. Silvio Kosutic, "Recent developments of Earth observation techniques for land and water engineering" delivered by Prof. Guido D' Urso, "dTDR as an optimisation tool for advanced process monitoring in biowaste treatment" given by Cornelius Jantschke and "Motion path planning and trajectory computation for a biomass processing robot" presented by Nikica Starcevic.

In the Topic Sessions, each starting with a review report, 52 papers were discussed, in oral presentation. At the Closing Session the Convenor emphasised the role of EurAgEng and CIGR in the ecologically sustainable development of agriculture and in the preservation of cultural heritage within the East-European countries.

During the Symposium round-table Meetings of CIGR, AAESEE, ERA and EurAgEng representatives were held, focusing on the main topics, achievements and trends of the SEEERA Pilot project. The project aims at integrating EU member states and South East European countries by linking research activities within existing national, bilateral and regional R \& D programmes. The participants agreed that there is a real need and high time for South East Europe countries, regardless to their recent status, to strongly enhance research cooperation by fostering integration of South East Europe into the growing European Research Area.

World famous agricultural machinery producers, such as AGCO, Case-New Holland, Claas, Hardi and others presented their current programmes by means of video and oral presentations during afternoon Sessions.

Information regarding the $36^{\text {th }}$ Symposium in the year 2008 will soon be available at the web site:

http://www.agr.hr/aed/index.htm

Prof. Silvio Kosutic

Convenor of the Symposium

Prof. Daniele De Wrachien Past President of EurAgEng 